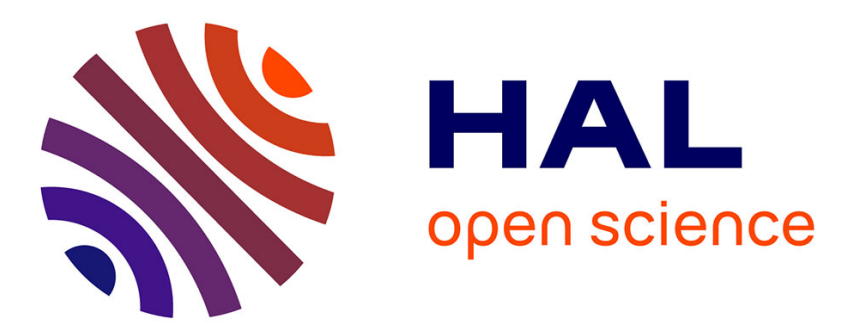

\title{
Competition between NarL-dependent activation and Fis-dependent repression controls expression from the Escherichia coli yeaR and ogt promoters
}

Derrick J P Squire, Meng Xu, Jeffrey A Cole, Stephen J W Busby, Douglas F Browning

\section{To cite this version:}

Derrick J P Squire, Meng Xu, Jeffrey A Cole, Stephen J W Busby, Douglas F Browning. Competition between NarL-dependent activation and Fis-dependent repression controls expression from the Escherichia coli yeaR and ogt promoters. Biochemical Journal, 2009, 420 (2), pp.249-257. 10.1042/BJ20090183 . hal-00479159

\section{HAL Id: hal-00479159 https://hal.science/hal-00479159}

Submitted on 30 Apr 2010

HAL is a multi-disciplinary open access archive for the deposit and dissemination of scientific research documents, whether they are published or not. The documents may come from teaching and research institutions in France or abroad, or from public or private research centers.
L'archive ouverte pluridisciplinaire HAL, est destinée au dépôt et à la diffusion de documents scientifiques de niveau recherche, publiés ou non, émanant des établissements d'enseignement et de recherche français ou étrangers, des laboratoires publics ou privés. 


\section{Competition between NarL-dependent activation and Fis-dependent repression controls expression from the Escherichia coli yeaR and ogt promoters}

Derrick J. P. Squire", Meng Xü, Jeffrey A. Cole, Stephen J. W. Busby* and Douglas F. Browning

School of Biosciences, University of Birmingham, Edgbaston, Birmingham B15 2TT, UK

\#contributed equally to this work

*To whom correspondence should be addressed s.j.w.busby@bham.ac.uk +44 (0)1214145439

Keywords: NarL, nitrate, Fis, promoters, reactive nitrogen species, DNA repair Running title: Transcription activation by E. coli NarL protein 


\begin{abstract}
The Escherichia coli NarL protein is a global gene regulatory factor that activates transcription at many target promoters in response to nitrate and nitrite ions. Although most NarL-dependent promoters are also co-dependent on a second transcription factor, FNR, two targets, the yeaR and ogt promoters are activated by NarL alone with no involvement of FNR. Biochemical and genetic studies presented here show that activation of the yeaR promoter is dependent on the binding of NarL to a single target centred at position -43.5 , whilst activation at the ogt promoter requires NarL binding to tandem DNA targets centred at position -45.5 and $\mathbf{7 8 . 5}$. NarL-dependent activation at both the yeaR and ogt promoters is decreased in rich medium and this depends on Fis, a nucleoid-associated protein. DNAse I footprinting studies identified Fis binding sites that overlap the yeaR promoter NarL site at position -43.5 , and the ogt promoter NarL site at position $\mathbf{- 7 8 . 5}$, and suggest that Fis represses both promoters by displacing NarL. The ogt gene encodes an $0^{6}$-alkylguanine DNA alkyltransferase and, hence, this is the first report of expression of a DNA repair function being controlled by nitrate ions.
\end{abstract}

\title{
INTRODUCTION
}

Transcription in Escherichia coli is orchestrated by a complex network of protein factors that regulate promoter activity in response to different external signals. Many factors interact at multiple promoters, and transcription initiation at many promoters is regulated by two or more factors [1,2]. The E. coli NarL protein is a typical response-regulator family transcription factor that controls responses to nitrate and nitrite ions in the environment. Its activity is induced by phosphorylation by two inner membrane-bound sensor kinases, NarX and NarQ, which are activated by nitrate and nitrite ions in the periplasmic space [3-7]. NarL controls the expression of many proteins involved in anaerobic respiration and, at most of its known promoter targets, it co-regulates transcription together with another global transcription factor, FNR, the 'master' regulator of anaerobic adaptation [2,8-10]. However, a study of the NarL regulon based on transcriptome analysis [11] identified some genes that appeared to be activated by NarL without FNR, and a thorough genetic analysis of the yeaRyoaG operon regulatory region by Valley Stewart and colleagues proved that NarL activates the yeaR promoter independently of FNR [12]. Here we describe the first biochemical study of the E. coli yeaR promoter and we show that NarL-dependent promoter activation can be reproduced in vitro. During our studies, we noticed that yeaR promoter activity is sharply reduced during bacterial growth in rich media and we present evidence that this is due to the action of Fis, a well-characterised DNA binding protein that is thought to play a key role in compaction of the E. coli chromosome [13]. In the second part of this study, we selected another E. coli promoter, the ogt promoter, that transcriptome analysis [11] had predicted to be activated by NarL alone, and we have used biochemical and genetic analysis to compare its expression and organisation with the yeaR promoter.

\section{EXPERIMENTAL PROCEDURES}

Strains, plasmids, promoter fragments and oligodeoxynucleotide primers

E. coli K-12 strains, plasmids and primers used in this study are listed in Table 1 . The JCB387 $\Delta f n r$ derivative was made by P1 transduction of a $\Delta f n r\left(\mathrm{~cm}^{R}\right)$ mutation that had been constructed in strain MG1655 by Constantinidou et al. [11]. Standard techniques for recombinant DNA manipulation were used throughout.

Promoter fragments were amplified by PCR using primers that introduced flanking EcoRI and HindllI sites. By convention, promoter sequences are numbered with respect to the transcription start point $(+1)$ and with upstream and downstream locations denoted by "-" and "+" prefixes, respectively. The E. coli K-12 yeaR-yoaG promoter fragment, yeaR100, was amplified from genomic DNA using primers pyeaRfw and pyeaRrev, and consisted of nucleotide sequences from positions -294 to +96 . The ogt100 promoter fragment was amplified using primers pogtfw and pogtrev, and consists of nucleotide sequences from 
position -269 to +51 . For the generation of DNA fragments for EMSA and footprinting, the yeaR100 and ogt100 fragments were cloned into plasmid pSR, encoding resistance to ampicillin [14]. To assay promoter activities, fragments were cloned into the low-copy number lac expression vector plasmid, pRW50, encoding resistance to tetracycline [15].

The ogt102 and ogt104 promoter fragments, in which the NarL I or NarL II binding sites were disrupted, were constructed using two-step megaprimer PCR. Promoter DNA was amplified using primer pSRdown and either primer ogt102 or primer ogt104 with pSR/ogt100 as template. The purified PCR products were used in a second round of PCR with primer D5431 and pSR/ogt100 as template. Purified products were restricted with EcoRI and HindIII and sub-cloned into pRW50.

\section{$\beta$-galactosidase activity assays}

Plasmids containing either the yeaR::lacZ or ogt::lacZ promoter fusions were transformed into relevant strains. $\beta$-galactosidase activities were measured using the Miller [16] protocol. Cells were grown either in rich medium: Lennox broth $(2 \%(\mathrm{w} / \mathrm{v})$ peptone (Oxoid), $1 \%(\mathrm{w} / \mathrm{v})$ yeast extract (Oxoid) and $170 \mathrm{mM} \mathrm{NaCl}$ ) plus $0.4 \%$ glucose, or in minimal medium: minimal salts with $0.4 \%$ glycerol, $5 \%$ Lennox broth, $20 \mathrm{mM}$ fumarate and $20 \mathrm{mM}$ trimethylamine $N$ oxide $[11,17]$. Where indicated, sodium nitrate or sodium nitrite was added to cultures to final concentrations of $20 \mathrm{mM}$ and $2.5 \mathrm{mM}$ respectively. Cultures were grown in static sealed test tubes to an optical density between 0.4 and 0.6 (at $650 \mathrm{~nm}$ ). Activities were calculated as nmol ONPG hydrolysed $\mathrm{min}^{-1} \mathrm{mg}^{-1}$ dry cell mass and represent the average of three independent experiments.

\section{Protein preparations}

Preparation and purification of a fusion of maltose binding protein to NarL (MBP-NarL) was as described by Li et al. [18]. In all experiments, the mature native NarL protein was used after the MBP moiety had been cleaved from MBP-NarL using protease factor Xa (New England Biolabs) [18]. Purified Fis protein, that had been prepared according to Osuna et al. [19], was donated by Rick Gourse, and purified E. coli RNA polymerase holoenzyme was purchased from Epicentre technologies (Madison). Purified DA154 FNR was prepared as in Wing et al. [20].

\section{Electromobility shift assays}

Electromobility shift assays (EMSA) using purified NarL were as described by Browning et al. [21]. EcoRI-Hindlll digested yeaR100 or ogt100 promoter fragments were end-labelled with $\left[\gamma^{32} \mathrm{P}\right]-\mathrm{ATP}$, and approximately $0.5 \mathrm{ng}$ of each fragment was incubated with different amounts of NarL. The reaction buffer contained $10 \mathrm{mM}$ potassium phosphate $(\mathrm{pH} 7.5), 100$ $\mathrm{mM}$ potassium glutamate, $1 \mathrm{mM}$ EDTA, $50 \mu \mathrm{M}$ DTT, $5 \%$ glycerol, $25 \mu \mathrm{g} \mathrm{m}{ }^{-1}$ herring sperm DNA and $50 \mathrm{mM}$ acetyl phosphate (final reaction volume was $10 \mu \mathrm{l}$ ). After incubation at $37^{\circ} \mathrm{C}$ for 30 minutes, samples were run in $0.25 \times$ TBE on a $6 \%$ polyacrylamide gel $\left(12 \mathrm{~V} \mathrm{~cm}^{-1}\right)$ containing 2\% glycerol and analysed using Bio-Rad Molecular Imager FX and Quantity One software (Bio-Rad). EMSA experiments with DA154 FNR were run as described by Browning et al. [22].

\section{DNase I and potassium permanganate footprinting experiments}

The protocols of Savery et al. [23] were used for footprinting experiments with ${ }^{32} \mathrm{P}$-endlabeled Aatll-HindIII fragments carrying the yeaR or ogt promoters. Each reaction $(20 \mu \mathrm{l})$ contained a final concentration of $1.35 \mathrm{nM}$ template DNA. The buffer composition was 20 mM HEPES ( $\mathrm{pH} 8.0$ ), $50 \mathrm{mM}$ potassium glutamate, $5 \mathrm{mM} \mathrm{MgCl}, 1 \mathrm{mM}$ DTT, $500 \mu \mathrm{g} \mathrm{ml}^{-1}$ bovine serum albumin and $25 \mathrm{\mu g} \mathrm{ml}^{-1}$ herring sperm DNA. NarL protein was pre-incubated with $50 \mathrm{mM}$ acetyl phosphate for $45 \mathrm{~min}$ at $37^{\circ} \mathrm{C}$, to allow for NarL phosphorylation and DNA binding [24]. In the competition experiments shown in Figures $2 \mathrm{~B}$ and 5B, NarL and Fis, were premixed prior to incubation with the labeled DNA fragment. 
For potassium permanganate footprint experiments, herring sperm DNA was omitted and $E$. coli RNA polymerase holoenzyme was used at a final concentration of $50 \mathrm{nM}$. Samples were analyzed by electrophoresis in denaturing gels that were calibrated with the products of Maxam-Gilbert ' $G+A$ ' sequencing reactions of the labelled fragment. Data were captured using a Bio-Rad Molecular Imager FX and Quantity One software (Bio-Rad).

\section{RESULTS}

\section{Analysis of the yeaR promoter}

The starting point of this work was the yeaR100 DNA fragment that carries the DNA sequence from position -294 to position +96 with respect to the yeaR promoter transcript start site. NarL recognises 7 base pair sequence elements (the NarL heptamer) and, at many promoters, two of these elements are organised as an inverted repeat, separated by 2 base pairs (the 7-2-7 site) [4]. Figure 1A shows the DNA sequence of the yeaR promoter region, highlighting the 7-2-7 NarL target centred at position -43.5 that was identified by Lin et al. [12]. Using mutational analysis, Lin et al. showed that NarL binding at this target activates the yeaR promoter. To confirm this, the yeaR100 fragment was cloned into pRW50, a low copy number lacZ expression vector to generate a yeaR::/ac fusion, and Figure 1B shows measurements of the expression of this fusion. In the JCB387 narL ${ }^{+}$strain, expression is strongly induced by both nitrate and nitrite ions and this induction is not found in the JCB3883 narL background. To measure binding of NarL to the yeaR100 fragment directly, we used EMSA and DNase I footprinting with purified NarL. The EMSA experiment, illustrated in Figure 1C, shows that NarL causes a single clear shifted band, consistent with NarL binding a single target site. The DNase I experiment, illustrated in Figure 1D, shows that this NarL binding site corresponds to the 7-2-7 site centred at position -43.5 .

\section{A role for Fis at the yeaR promoter}

Whilst studying the expression of the yeaR */ac fusion, we noticed that nitrate-dependent induction was greater in minimal medium than in more nutrient-rich media. In our previous work, we had discovered that the nucleoid-associated protein, Fis, plays a direct role in the repression of several promoters in response to nutrient abundance and rapid growth $[22,25,26]$. Thus, to investigate any role of $F$ is at the yeaR promoter, expression of the yeaR::lac fusion was compared in strain JCB387 and a fis mutant derivative, JCB3871. Results illustrated in Figure 2A show that nitrate-induced expression is sharply suppressed during growth in $L$ broth supplemented with glucose, and that this suppression is greatly reduced in the JCB3871 fis strain. DNase I footprinting with purified Fis protein was then used to investigate whether Fis interacts directly with the yeaR promoter. The results (Figure $2 \mathrm{~B}$ ) reveal that Fis binds to a target (Fis I) that overlaps the upstream end of the DNA site for NarL and, at higher Fis concentrations, a second site (Fis II), that overlaps the downstream end of the DNA site for NarL, is occupied. Furthermore, footprinting experiments with both Fis and NarL (Figure $2 \mathrm{~B}$ and $2 \mathrm{C}$ ) show that Fis prevents NarL binding to its target.

To investigate the effects of NarL and Fis on transcription initiation at the yeaR promoter, we used potassium permanganate footprinting, which can be exploited to monitor DNA unwinding during open complex formation [23]. Results in Figure 3A show that incubation of the $y e a R$ promoter fragment with holo RNA polymerase results in permanganate-induced DNA cleavage, indicating unwinding just upstream of the transcription startpoint. As expected, preincubation with NarL increases this cleavage, most likely as NarL promotes the formation of a transcriptionally competent complex at the yeaR promoter. The experiment illustrated in Figure 3B shows that this unwinding is totally suppressed by Fis, both in the presence and absence of NarL.

\section{Analysis of the ogt promoter}

A previous transcriptome analysis had predicted that expression of the ogt gene is also activated by NarL independently of FNR [11]. To investigate whether the ogt and yeaR 
regulatory regions share common features, we generated the ogt100 DNA fragment that carries the DNA sequence from position -269 to position +51 with respect to the ogt transcript start site, and cloned it into pRW50, to give an ogt::lac fusion. Figure 4A shows the DNA sequence around the ogt promoter transcript start point and Figure 4B illustrates measurements of the expression of the fusion in the JCB387 narL ${ }^{+}$and JCB3883 narL strains. The data show that expression is strongly induced by nitrate ions and that this induction is not observed in the narL background. In contrast to the yeaR promoter, induction by nitrite is minimal.

An EMSA experiment showed that NarL binds to at least two sites at the ogt promoter (Figure 4C) and DNase I footprinting (Figure 4D) revealed two binding targets for NarL that appear to correspond to two 7-2-7 sites, centred at position -78.5 (NarL I) and -45.5 (NarL II) (highlighted in Figure 4A). To investigate the function of these two targets, derivatives of the ogt100 fragment, ogt102 and ogt104, were constructed in which the NarL I or NarL II sites respectively were inactivated by mutations (shown in Figure 4A). Each fragment was cloned into pRW50 and Table 2 lists measurements of the expression of the resulting ogt::lac fusions. The data show that nitrate-dependent activation of the ogt promoter is suppressed by mutations in either of the two DNA sites for NarL.

In a further EMSA experiment, we found that purified FNR gave no clear shifted band with the ogt100 DNA fragment, suggesting that the pogt region contains no specific DNA site for FNR (data not shown). To check directly for any involvement of FNR in regulating the ogt promoter, nitrate-dependent induction of the ogt::lac fusion in strain JCB387 was compared with induction in a $\Delta f n r$ derivative. Results presented in Figure $4 \mathrm{E}$ show that FNR has no significant effect on expression from the ogt promoter.

Fis represses the ogt promoter by displacing upstream-bound NarL

To investigate any role of Fis at the ogt promoter, expression of the ogt::lac fusion was compared in strain JCB387 and in the fis mutant derivative, JCB3871. Results illustrated in Figure $5 \mathrm{~A}$ show that nitrate-induced expression is sharply suppressed during growth in $\mathrm{L}$ broth supplemented with glucose, and that this suppression is greatly reduced in the JCB3871 fis strain. DNase I footprinting with purified Fis protein was then used to investigate whether Fis interacts directly at the ogt promoter. The results, illustrated in Figure 5B, identify a target for Fis that overlaps the upstream site for NarL. Footprinting experiments with both Fis and NarL show that Fis prevents NarL binding to its upstream target at position -78.5 , whilst not affecting binding at the downstream target (Figure $5 \mathrm{~B}$ and $5 \mathrm{C}$ ).

\section{DISCUSSION}

Most $E$. coli transcription activators function by binding to specific sites at target promoters and then recruiting RNA polymerase via a direct contact, and there are three major classes of activator-dependent promoter [27]. At Class I promoters, the activator binds upstream of the promoter - 35 element and recruits RNA polymerase by contacting the C-terminal domain of its a subunit. At Class II promoters, the activator overlaps the promoter -35 element and can contact both the RNA polymerase $\alpha$ and $\sigma$ subunits. At some promoters, recruitment of RNA polymerase requires more than one contact. At these promoters, known as Class III promoters, two or more activators make independent contacts with different targets in RNA polymerase [28]. Although NarL appears to be a typical transcription activator belonging to the response-regulator family, at most of its previously studied target promoters [4], it coactivates promoter activity in conjunction with FNR, the master regulator for the adaptation of $E$. coli to growth in the absence of oxygen [8]. The likely explanation for this is that most of the genes controlled by these promoters encode products that play a role in anaerobic respiration of nitrate and nitrite, and thus their expression is fully induced only in both the absence of oxygen (signalled via FNR) and the presence of nitrate or nitrite (signalled by NarL) $[4,29,30]$. However, the transcriptomics study of Constantinidou et al. [11] predicted that a small number of $E$. coli promoters are activated by NarL without FNR, and the 
comprehensive genetic analysis of the yeaR promoter by Lin et al. [12] showed that binding of NarL to a site that overlaps the promoter -35 element is sufficient to activate transcription without FNR. Here, using biochemical methods, we confirmed that purified NarL binds to this target and can activate open complex formation, most likely functioning as a Class II activator. The lack of induction of the yeaR promoter in a narL mutant background argues that NarP, which is a homologue of NarL, plays little or no role here. Recall that NarP is also activated in response to nitrate and can bind to 7-2-7 NarL binding targets [4,24]. In supplementary experiments, we found that the introduction of a narP mutation into either JCB387 or JCB3883 had very little effect on yeaR promoter activity (D.J.P.S, unpublished results).

Although the function of the products of the yeaR-yoaG operon is unknown, an important clue comes from the observation that the yeaR promoter is repressed by the binding of NsrR to a target that overlaps the -10 hexamer element (Figure 1A)[12,31,32]. Hence, even if NarL activity is triggered by nitrate or nitrite ions, the yeaR-yoaG operon will not be expressed unless repression by NsrR is lifted. Recent studies have identified NsrR as a transcriptional repressor that controls the expression of a regulon concerned with bacterial responses to reactive nitrogen species (RNS), such as nitric oxide [32-34]. NsrR contains an iron-sulphur cluster that senses RNS, which convert NsrR to a form that is unable to bind at its targets, and hence unable to function as a repressor [35-37]. Our best guess is that most of the genes in the NsrR regulon encode products needed for RNS detoxification and the repair of damage caused by RNS. It is known that RNS are generated during anaerobic respiration of nitrate and nitrite [38-40], and hence it is easy to envisage that the yeaR-yoaG operon helps manage some aspect of RNS stress, after its expression is co-induced by external nitrate or nitrite ions (sensed by NarL) and RNS (sensed by NsrR). If this is the case, it makes sense for the yeaR promoter to be independent of FNR, since some RNS inactivate FNR $[38,41]$.

During our experiments we noticed that nitrate-dependent induction at the yeaR promoter is greatly reduced during growth in rich media and we propose that this is due to the action of Fis protein. Recall that Fis is a sequence-specific DNA binding protein that plays many roles in $E$. coli including contributing to compaction of the folded chromosome and regulating promoter activity [13,42]. Crucially, levels of Fis fluctuate dramatically, with over 50,000 molecules per cell in rapidly growing cells in rich media, and greatly decreased levels during slow growth, for example in poor media or during starvation $[43,44]$. Whole genome studies using chromatin immunoprecipitation have shown that Fis can interact at hundreds of targets in the $E$. coli genome, and that over $60 \%$ of these targets are in gene regulatory regions $[45,46]$. Our in vitro studies (Figure 2) show that purified Fis binds to two targets at the yeaR promoter that flank the DNA site for NarL. Fis binding can displace NarL and this stops open complex formation (Figure 3). Thus, we propose that, in conditions where Fis levels are raised, Fis binds at the yeaR promoter and prevents nitrate-dependent induction by blocking NarL binding to its target (illustrated in Figure 6A). This explains why the reduction of nitratedependent induction at the yeaR promoter, found in rich media, is lost in a fis mutant strain.

In the second part of our work, we investigated the $E$. coli ogt promoter, which Constantinidou et al. [11] had also found to be induced by NarL independently of FNR. Note that a previous study [47] had identified the transcription start of the ogt promoter and its -10 element but did not investigate its regulation. Our results confirm that the ogt promoter is induced by NarL in response to nitrate ions, without help from FNR. However, in contrast to the situation at the yeaR promoter, induction requires the binding of NarL to two 7-2-7 sites, and the ogt promoter appears to be a Class III promoter. A possible explanation for this is that NarL binding at the ogt promoter is $\sim 10$ times weaker than binding at the yeaR promoter, and this may also account for its lack of induction by nitrite ions, which are known to result in lower levels of active NarL [4]. As at the yeaR promoter, the ogt promoter is not induced in a narL mutant background, suggesting that NarP also plays little or no role here. 
In agreement, we found that the introduction of a narP mutation into either JCB387 or JCB3883 had very little effect on ogt promoter activity (M.X., unpublished results).

In contrast to the yeaR promoter, the ogt promoter is not a target for NsrR [32]. A clue to understanding the rationale for this comes from the work of Margison and colleagues $[47,48]$, who were the first to clone and sequence the $E$. coli ogt gene and to investigate its promoter. These authors identified the ogt gene product as an $\mathrm{O}^{6}$-alkylguanine DNA alkyltransferase that removes alkyl groups from chemically damaged guanine residues in DNA. We suggest that the key to understanding why the expression of this DNA repair gene product is induced by nitrate ions is that RNS cause damage to DNA as well as to proteins [39,49-52]. In particular, RNS can cause lysine sidechains in proteins and some free aminoacids to become potent DNA methylating agents. We suggest that the induction of ogt by NarL alone in response to external nitrate provides a prophylactic insurance policy against possible genotoxic effects arising from nitrate metabolism. As at the yeaR promoter, nitrate-dependent induction can be repressed by Fis that binds to a single site overlapping the upstream DNA site for NarL. We propose that, in conditions where Fis levels are raised, Fis binds at this target and prevents nitrate-dependent induction by blocking NarL binding to its target (illustrated in Figure 6B).

It is known that the expression of many non-essential genes is repressed in rapidly growing cells, where a large proportion of the available RNA polymerase is channelled to the essential genes for protein synthesis and cell growth, and in some cases, this repression is due to Fis $[22,25,26]$. Although there is no simple rationale for why the yeaR and ogt promoters are also repressed by Fis, we suggest that rapidly growing cells may opt out of certain stress responses, and we speculate that RNS may be a small risk in these conditions compared to other stresses. Remarkably, at both promoters, the mechanism of action of Fis is similar, with Fis binding to targets that overlap a DNA site for NarL, thereby preventing binding of an essential activator.

\section{ACKNOWLEDGEMENTS}

We thank the Wellcome Trust for funding this work with a programme grant. D.J.P.S was supported by a BBSRC studentship. We are grateful to Rick Gourse for donating purified Fis protein and Kevin Chipman for helpful discussions.

\section{REFERENCES}

1. Salgado, H., Santos-Zavaleta, A., Garma-Castro, S., Peralto-Gil, M., PenalozaSpinola, M.I., Martinez-Antonio, A., Karp, P.D. and Collado-Vides, J. (2006) The comprehensive updated regulatory network of Escherichia coli K-12. BMC Bioinformatics doi:10.1186/1471-2105-7-5

2. Karp, P.D., Keseler, I.M., Shearer, A., Latendresse, M., Krummenacker, M., Paley, S.M., Paulsen, I., Collado-Vides, J., Gama-Castro, S., Peralta-Gil, M., SantosZavaleta, A., Penaloza-Spinola, M.I., Bonavides-Martinez, C. and Ingraham, J. (2007) Multidimensional annotation of the Escherichia coli K-12 genome. Nucl. Acids Res. 35, 7577-7590

3. Baikalov, I., Schroder, I., Kaczor-Grzeskowiak, M., Grzeskowiak, K., Gunsalus, R. and Dickerson, R. (1996) Structure of the Escherichia coli response regulator, NarL. Biochemistry 35,11053-11061

4. Darwin, A.J. and Stewart, V. (1996) The NAR modulon systems: nitrate and nitrite regulation of anaerobic gene expression. In Regulation of gene expression in Escherichia coli (Lin, E. and Lynch, A., eds) pp 343-359, R.G. Landes Company, Austin, TX

5. Lee, A.I., Delgado, A. and Gunsalus, R.P. (1999) Signal-dependent phosphorylation of the membrane-bound NarX two-component sensor-transmitter protein of Escherichia coli: nitrate elicits a superior anion ligand response compared to nitrite. J. Bacteriol. 181, 5309-5316 
6. Zhang, J.H., Xioa, G., Gunsalus, R. and Hubbell, W.L. (2003) Phosphorylation triggers domain separation in the DNA binding response regulator, NarL. Biochemistry 42, 2552-2559

7. Stewart V. (2003) Nitrate- and nitrite-responsive sensors NarX and NarQ of proteobacteria. Biochem. Soc. Trans. 31,1-10

8. Spiro, S. and Guest, J.R. (1990) FNR and its role in oxygen-regulated gene expression in Escherichia coli. FEMS Microbiol. Rev. 6, 399-428

9. Salmon, K., Hung, S.P., Mekjian, K., Baldi. P., Hatfield, G.W. and Gunsalus, R.P. (2003) Global gene expression profiling in Escherichia coli K12. The effects of oxygen availability and FNR. J. Biol. Chem. 278, 29837-29855

10. Kang, Y., Weber, K.D., Qiu, Y., Kiley, P.J. and Blattner, F.R. (2005) Genome-wide expression analysis indicates that FNR of Escherichia coli K-12 regulates a large number of genes of unknown function. J. Bacteriol. 187, 1135-1160

11. Constantinidou, C., Hobman, J.L., Griffiths, L., Patel, M.D., Penn, C.W., Cole, J.A. and Overton, T.W. (2006) A reassessment of the FNR regulon and transcriptomic analysis of the effects of nitrate, nitrite, NarXL, and NarQP as Escherichia coli K12 adapts from aerobic to anaerobic growth. J. Biol. Chem. 281 4802-4815

12. Lin, H.Y., Bledsoe, P.J. and Stewart, V. (2007) Activation of yeaR-yoaG operon transcription by the nitrate-responsive regulator NarL is independent of oxygenresponsive regulator Fnr in Escherichia coli K-12. J. Bacteriol. 189, 7539-7548.

13. McLeod, S.M. and Johnson, R.C. (2001) Control of transcription by nucleoid proteins. Curr. Opin. Microbiol. 4,152-159

14. Kolb, A., Kotlarz, D., Kusano, S. and Ishihama, A. (1995) Selectivity of the E. coli RNA polymerase E sigma 38 for overlapping promoters and ability to support CRP activation. Nucl. Acids Res. 23, 819-826

15. Lodge, J., Fear, J., Busby, S., Gunasekaran, P. and Kamini, N-R. (1992) Broad host range plasmids carrying the Escherichia coli lactose and galactose operons. FEMS Microbiol. Lett. 95, 271-276

16. Miller, J. (1972) Experiments in Molecular Genetics. Cold Spring Harbor, NY; Cold Spring Harbor Laboratory Press.

17. Pope, N.R. and Cole, J. (1982) Generation of a membrane potential by one of two independent pathways of nitrite reduction by E. coli. J. Gen. Microbiol. 128, 319-322

18. Li, J., Kustu, S. and Stewart, V. (1994) In vitro interaction of nitrate-responsive regulatory protein NarL with DNA target sequences in the fdnG, narG, narK and frdA operon control regions of Escherichia coli K-12. J. Mol. Biol. 241, 150-165

19. Osuna, R., Finkel, S.E. and Johnson, R.C. (1991) Identification of two functional regions in Fis: the $\mathrm{N}$-terminus is required to promote Hin-mediated DNA inversion but not lambda excision. EMBO J. 10,1593-1603

20. Wing, H.J., Green, J., Guest, J.R. and Busby, S.J. (2000) Role of activating region 1 of Escherichia coli FNR protein in transcription activation at class II promoters. J. Biol. Chem. 275, 29061-29065

21. Browning, D.F., Beatty, C.M., Wolfe, A.J., Cole, J.A. and Busby, S.J.W. (2002) Independent regulation of the divergent Escherichia coli nrfA and acsP1 promoters by a nucleoprotein assembly at a shared regulatory region. Mol. Microbiol. 43, 687701

22. Browning, D.F., Grainger, D.C., Beatty, C.M., Wolfe, A.J., Cole, J.A. and Busby, S.J.W. (2005) Integration of three signals at the Escherichia coli nrf promoter: a role for Fis protein in catabolite repression. Mol. Microbiol. 57, 496-510

23. Savery, N.J., Belyaeva, T. and Busby, S.J. (1996) Introduction to protein:DNA interactions, DNase I footprinting, hydroxyl radical footprinting, permanganate footprinting and supplementary protocols. In Essential Techniques: Gene Transcription. Docherty, K (ed.). Oxford: BIOS Scientific Publishers, pp. 1-5 and 2133. 
24. Darwin, A.J, Tyson, K.L. Busby, S. and Stewart, V. (1997) Differential regulation by homologous response regulators NarL and NarP of Escherichia coli K-12 depends on DNA binding site arrangement. Mol. Microbiol. 25, 583-595

25. Browning, D.F., Beatty, C.M., Sanstad, E.A., Gunn, K.A., Busby, S.J.W. and Wolfe, A.J. (2004) Modulation of CRP-dependent transcription at the Escherichia coli acsP2 promoter by nucleoprotein complexes: anti-activation by the nucleoid proteins FIS and IHF. Mol. Microbiol. 51, 241-254

26. Grainger, D.C., Goldberg, M.D., Lee, D.J. and Busby, S.J. (2008) Selective repression by Fis and $\mathrm{H}-\mathrm{NS}$ at the Escherichia coli dps promoter. Mol. Microbiol. 68, 1366-1377

27. Busby, S. and Ebright, R.H. (1994) Promoter structure, promoter recognition and transcription activation in prokaryotes. Cell 79, 743-746

28. Busby, S.J.W. and Savery, N.J. (2007) Transcription activation at bacterial promoters. In Encyclopaedia of Life Sciences. John Wiley \& Sons, Ltd: Chichester http://www.els.net/ [doi:10.1002/978047001.5902.a0000855.pub2]

29. Wang, H. and Gunsalus, R.P. (2000) The nrfA and nirB nitrite reductase operons in Escherichia coli are expressed differently in response to nitrate than to nitrite. J. Bacteriol. 182, 5813-5822

30. Wang, H. and Gunsalus, R.P. (2003) Coordinate regulation of the Escherichia coli formate dehydrogenase $f d n G H I$ and $f d h F$ genes in response to nitrate, nitrite, and formate: roles for NarL and NarP. J. Bacteriol. 185, 5076-5085

31. Justino, M.C., Vicente, J.B., Teixeira, M. and Saraiva, L.M. (2005) New genes implicated in the protection of anaerobically grown Escherichia coli against Nitric Oxide. J. Biol. Chem. 280, 2636-2643

32. Filenko, N., Spiro, S., Browning, D.F., Squire, D., Overton, T.W., Cole, J. and Constantinidou, C. (2007) The NsrR regulon of Escherichia coli K-12 includes genes encoding the hybrid cluster protein and the periplasmic, respiratory nitrite reductase. J. Bacteriol. 189, 4410-4417

33. Rodionov, D.A., Dubchak, I.L., Arkin, A.P., Alm, E.J. and Gelfand, M.S. (2005) Dissimilatory metabolism of nitrogen oxides in bacteria: comparative reconstruction of transcriptional networks. PLoS Comput. Biol. e55

34. Bodenmiller, D.M. and Spiro, S. (2006) The yjeB (nsrR) gene of Escherichia coli encodes a nitric oxide-sensitive transcriptional regulator. J. Bacteriol. 188, 874-881

35. Tucker, N.P., Hicks, M.G., Clarke, T.A., Crack, J.C., Chandra, G., Le Brun, N.E., Dixon, R. and Hutchings, M.I. (2008) The transcriptional repressor protein NsrR senses nitric oxide direcly via a $2 \mathrm{Fe}-2 \mathrm{~S}$ cluster. PLoS ONE 3, e3623

36. Isabella, V.M., Lapek, J.D., Kennedy, E.M. and Clark, V.M. (2009) Functional analysis of NsrR, a nitric oxide-sensing Rrf2 repressor in Neisseria gonorrhoeae. Mol. Microbiol. in the press

37. Yukl, E.T., Elbaz, M.A., Nakano, M.M. and Moenne-Luccos, O. (2009) Transcription Factor NsrR from Bacillus subtilis Senses Nitric Oxide with a 4Fe-4S Cluster. Biochemistry in the press

38. Corker, H. and Poole, R.K. (2003) Nitric oxide formation by Escherichia coli. Dependence on nitrite reductase, the NO-sensing regulator Fnr, and flavohemoglobin, Hmp. J. Biol. Chem. 278, 31584-31592

39. Weiss, B. (2006) Evidence for mutagenesis by nitric oxide during nitrate metabolism in Escherichia coli. J. Bacteriol. 188, 829-833

40. Spiro, S. (2007) Regulators of bacterial responses to nitric oxide. FEMS Microbiol. Rev. 31,193-211

41. Cruz-Ramos, H., Crack, J., Wu, G., Hughes, M. N., Scott, C., Thomson, A. J., Green, J. and Poole, R.K. (2002) NO sensing by FNR: regulation of the Escherichia coli NOdetoxifying flavohaemoglobin, Hmp. EMBO J. 21, 3235-3244

42. Finkel, S.E. and Johnson, R.C. (1992) The Fis protein: it's not just for DNA inversion anymore. Mol. Microbiol. 6, 3257-3265 
43. Ball, C.A., Osuna, R., Ferguson, K.C. and Johnson, R.C. (1992) Dramatic changes in Fis levels upon nutrient upshift in Escherichia coli. J. Bacteriol. 174, 8043-8056

44. Talukder, A.A., Iwata, A., Nishimura, A., Ueda, S., and Ishihama, A. (1999) Growth phase-dependent variation in protein composition of the Escherichia coli nucleoid. J. Bacteriol. 181, 6361-6370

45. Grainger, D.C., Hurd, D., Goldberg, M.D. and Busby, S.J. (2006) Association of nucleoid proteins with coding and non-coding segments of the Escherichia coli genome. Nucl. Acids Res. 34, 4642-4652

46. Cho. B-K., Knight, E.M., Barrett, C.L., and Palsson, B.O. (2008) Genome-wide analysis of Fis binding in Escherichia coli indicates a causative role for A-/AT-tracts. Genome Res. 18, 900-910

47. Potter, P.M., Wilkinson, M.C., Fitton, J., Carr, F.J., Brennand, J., Cooper, D.P. and Margison, G.P. (1987) Characterisation and nucleotide sequence of ogt, the $\mathrm{O}^{6}$ alkylguanine-DNA-alkyltransferase gene of E. coli. Nucl. Acids Res. 15, 9177-9193

48. Margison, G.P., Cooper, D.P. and Brennand, J. (1985) Cloning of the E. coli O ${ }^{6}$ methyl guanine and methylphosphotriester methyltransferase gene using a functional DNA repair assay. Nucl. Acids Res. 13,1939-1952

49. Swann, P.F. and Magee, P.N. (1968) Nitrosamine-induced carcinogenesis. The alkylation of nucleic acids of the rat by $\mathrm{N}$-methyl-N-nitrosourea, dimethylnitrosamine, dimethyl sulphate and methyl methanesulphonate. Biochem. J. 110, 39-47

50. Kunisaki, N. and Hayashi, M. (1979) Formation of $N$-nitrosamines from secondary amines and nitrite by resting cells of Escherichia coli B. Applied Env. Microbiol. 37, 279-282

51. Taverna, P. and Sedgwick, B. (1996) Generation of an endogenous DNA-methylating agent by nitrosation in Escherichia coli. J. Bacteriol. 178, 5105-5111

52. Sedgwick, B. (1997) Nitrosated peptides and polyamines as endogenous mutagens in $\mathrm{O}^{6}$-alkylguanine-DNA alyltransferase deficient cells. Carcinogenesis 18, 15611567

53. Page, L., Griffiths, L. and Cole, J.A. (1990) Different physiological roles of two independent pathways for nitrite reduction to ammonia by enteric bacteria. Arch. Microbiol. 154, 349-354

54. Tyson, K.L., Bell, A.I., Cole, J.A. and Busby, S.J.W. (1993) Definition of nitrite and nitrate response elements at the anaerobically inducible Escherichia coli nirB promoter: interactions between FNR and NarL. Mol. Microbiol. 7, 151-157

55. Wu, H., Tyson, K.L., Cole, J.A. and Busby S.J.W. (1998) Regulation of transcription initiation at the Escherichia coli nir operon promoter: a new mechanism to account for co-dependence on two transcription factors. Mol. Microbiol. 27, 493-505 


\section{FIGURE LEGENDS}

Figure 1. NarL regulates the Eschericia coli yeaR promoter.

(A) The panel shows the Escherichia coli K-12 yeaR promoter sequence from positions -64 to +86 with respect to the transcription start site $(+1)(12)$. The -10 hexamer element is bold and underlined, the transcription start point is designated by a lower case letter and a bent arrow, and the translation start ATG codon is underlined. The DNA sites for NarL and NsrR are identified by shaded arrows and a rectangle, respectively, and the centre of each site is numbered with respect to the transcription start site. (B) The panel shows measured $\beta$ galactosidase activities in JCB387 and JCB3883 (narL) cells carrying pRW50, containing the yeaR100 promoter fragment. Cells were grown in minimal medium (MM) and, where indicated, sodium nitrate or nitrite was added to a final concentration of $20 \mathrm{mM}$ and $2.5 \mathrm{mM}$, respectively. $\beta$-galactosidase activities are expressed as nmol of ONPG hydrolysed $\mathrm{min}^{-1}$ $\mathrm{mg}^{-1}$ dry cell mass. (C) The panel shows EMSA experiments with purified NarL protein. Endlabelled yeaR100 promoter fragment was incubated with increasing concentrations of NarL and protein-DNA complexes were separated by polyacrylamide gel electrophoresis. The concentration of NarL was: lane 1, no protein; lane 2, $0.2 \mu \mathrm{M}$ NarL; lane 3, $0.4 \mu \mathrm{M}$ NarL; lane 4, $0.8 \mu \mathrm{M}$ NarL; lane 5, $1.6 \mu \mathrm{M}$ NarL. (D) The panel shows an in vitro DNase I footprint experiment with purified NarL. End-labelled yeaR100 Aatll-Hindlll fragment was incubated with increasing concentrations of NarL and subjected to DNase I footprint analysis. The concentration of NarL was: lane 1, no protein; lane 2, 0.8 $\mu \mathrm{M}$; lane 3, $1.6 \mu \mathrm{M}$; lane 4, 3.2 $\mu \mathrm{M}$. The gel was calibrated using a Maxam-Gilbert ' $G+A$ ' sequencing reaction and relevant positions are indicated. The location of the DNA site for NarL is shown by a box and hypersensitive sites due to NarL binding are starred.

Figure 2. Fis represses transcription at the yeaR promoter.

(A) The panel shows $\beta$-galactosidase activities in JCB387 and JCB3871 (fis) cells carrying pRW50, containing the yeaR100 promoter fragment. Cells were grown in either minimal or rich media, which was supplemented with $20 \mathrm{mM}$ nitrate where indicated. $\beta$-galactosidase activities are expressed as nmol of ONPG hydrolyzed $\mathrm{min}^{-1} \mathrm{mg}^{-1}$ dry cell mass. (B) The panel shows an in vitro DNase I footprint experiment. End-labelled yeaR100 Aatll-HindIII fragment was incubated with increasing concentrations of Fis in combination with NarL, as indicated, and subjected to DNase I footprinting. The concentration of Fis was: lanes 1 and 6, no protein; lanes 2 and 7, $0.22 \mu \mathrm{M}$; lanes 3 and $8,0.45 \mu \mathrm{M}$; lanes 4 and 9, 0.90 $\mu \mathrm{M}$; lanes 5 and $10,1.8 \mu \mathrm{M}$. The concentration of NarL was $1.6 \mu \mathrm{M}$ in lanes $6-10$. The gel was calibrated using a Maxam-Gilbert ' $G+A$ ' sequencing reaction and relevant positions are indicated. The locations of DNA sites for NarL and Fis are indicated by vertical boxes. (C) Quantification of Fis and NarL binding. The binding of Fis and NarL to the yeaR100 promoter fragment was analysed using data from lane 5 (Fis only), lane 6 (NarL only) and lane 10 (Fis and NarL) in panel (B) with Quantity One Software (BioRad). Inverted arrows and rectangular boxes indicate the NarL and Fis binding sites, respectively, and selected locations are shown. In panels (B) and (C), hypersensitive sites at positions -52 and -40 , which are induced by NarL binding, are starred, whilst the hypersensitive site at position -29, which is induced by Fis binding to Fis II, is marked by a circle.

Figure 3. DNA opening at the yeaR promoter.

The figure shows results of in vitro potassium permanganate footprint experiments at the yeaR promoter. Gels were calibrated using Maxam-Gilbert ' $G+A$ ' sequencing reactions and the locations of some cleavage sites are shown. (A) End-labelled yeaR promoter AatllHindIII fragment was incubated with 50 nM RNA polymerase and NarL protein, as indicated, before permanganate treatment. NarL concentrations were: lanes 1 and 2, no NarL; lane 3, $0.1 \mu \mathrm{M}$; lane 4, 0.2 $\mu \mathrm{M}$; lane 5, $0.4 \mu \mathrm{M}$; lane 6, $0.8 \mu \mathrm{M}$. (B) End-labelled yeaR promoter Aatll-HindIII fragment was incubated with $50 \mathrm{nM}$ RNA polymerase, $0.4 \mu \mathrm{M}$ NarL and 0.45 $\mu \mathrm{M}$ Fis protein, as indicated, before permanganate treatment. 
Figure 4. NarL regulates the Escherichia coli ogt promoter.

(A) The panel shows the Escherichia coli K-12 ogt promoter sequence from position -106 to +57 with respect to the transcription start site $(+1)$ [47]. The -10 hexamer element is bold and underlined, the transcription start point is designated by a lower case letter and a bent arrow, and the translation start ATG codon is underlined. The DNA sites for NarL are identified by shaded arrows and the centre of each site is numbered with respect to the transcription start site. The base substitutions used to disrupt NarL I and NarL II are indicated above each site. (B) The panel shows measured $\beta$-galactosidase activities in JCB387 and JCB3883 (narL) cells carrying pRW50, containing the ogt100 promoter fragment. Cells were grown in minimal medium (MM) and, where indicated, sodium nitrate or nitrite was added to a final concentration of $20 \mathrm{mM}$ and $2.5 \mathrm{mM}$, respectively. $\beta$-galactosidase activities are expressed as nmol of ONPG hydrolysed $\mathrm{min}^{-1} \mathrm{mg}^{-1}$ dry cell mass. (C) The panel shows EMSA experiments with purified NarL protein. End-labelled ogt100 promoter fragment was incubated with increasing concentrations of NarL and protein-DNA complexes were separated by polyacrylamide gel electrophoresis. The concentration of NarL was: lane 1, no protein; lane 2, $0.2 \mu \mathrm{M}$ NarL; lane 3, $0.8 \mu \mathrm{M}$ NarL; lane 4, $1.6 \mu \mathrm{M}$ NarL; lane 5, 3.2 $\mu \mathrm{M}$ NarL. (D) The panel shows an in vitro DNase I footprint experiment with purified NarL. End-labelled ogt100 Aatll-HindlII fragment was incubated with increasing concentrations of NarL and subjected to DNase I footprint analysis. The concentration of NarL was: lane 1, no protein; lane 2, 0.4 $\mu \mathrm{M}$; lane 3, 0.8 $\mu \mathrm{M}$; lane 4, 1.6 $\mu \mathrm{M}$; lane 5, 3.2 $\mu \mathrm{M}$. The gel was calibrated using a Maxam-Gilbert ' $G+A$ ' sequencing reaction and relevant positions are indicated. The location of NarL binding sites is shown by boxes and a hypersensitive site due to NarL binding is starred. (E) The panel shows measured $\beta$-galactosidase activities in JCB387 and a $\Delta f n r$ derivative, carrying pRW50 containing the ogt100 promoter fragment. Cells were grown in minimal medium (MM) and, where indicated, $20 \mathrm{mM}$ sodium nitrate was added.

Figure 5. Fis represses transcription at the ogt promoter.

(A) The panel shows $\beta$-galactosidase activities in JCB387 and JCB3871 (fis) cells carrying pRW50, containing the ogt100 promoter fragment. Cells were grown in either minimal or rich media, which was supplemented with $20 \mathrm{mM}$ nitrate where indicated. $\beta$-galactosidase activities are expressed as nmol of ONPG hydrolyzed $\mathrm{min}^{-1} \mathrm{mg}^{-1}$ dry cell mass. (B) The panel shows an in vitro DNase I footprint experiment. End-labelled ogt100 Aatll-HindIII fragment was incubated with increasing concentrations of Fis in combination with NarL, as indicated, and subjected to DNase footprinting. The concentration of Fis was: lanes 1 and 6, no protein; lanes 2 and 7, 0.45 $\mu \mathrm{M}$; lanes 3 and $8,0.89 \mu \mathrm{M}$; lanes 4 and 9, $1.8 \mu \mathrm{M}$; lanes 5 and $10,3.8 \mu \mathrm{M}$. The concentration of NarL was $3.2 \mu \mathrm{M}$ in lanes $6-10$. The gel was calibrated with a Maxam-Gilbert ' $G+A$ ' sequencing reaction and relevant positions are indicated. The locations of DNA sites for NarL and Fis are indicated by vertical boxes. (C) Quantification of Fis and NarL binding. The binding of Fis and NarL to the ogt100 promoter fragment was analysed using data from lane 5 (Fis only), lane 6 (NarL only) and lane 10 (Fis and NarL) in panel (B) and Quantity One Software (BioRad). The inverted arrows and the rectangular box indicate the NarL and Fis binding sites, respectively, and selected locations are shown. In panels (B) and (C), the hypersensitive site at position -76 that is induced by NarL binding to NarL I is starred, and the Fis-induced hypersensitive site at position -90 is marked by a filled circle.

Figure 6. Regulation at the yeaR and ogt promoters by NarL and Fis.

The figure illustrates the juxtaposition of DNA sites for NarL and Fis at the Escherichia coli $y e a R$ and ogt promoter regions. DNA sites for NarL are shown as convergent arrows that represent 7-2-7 sites [4], and DNA sites for Fis are shown as horizontal shaded bars that identify the core 15 base pair target at each site [13]. Note that, because Fis induces sharp DNA bending [42], DNase I footprints of Fis extend beyond the core target. (A) When nitrate is present in minimal medium, transcription from the yeaR promoter is activated by NarL binding to the NarL site. In richer media, Fis represses transcription by binding to the Fis I and Fis II sites, thereby displacing NarL. (B) When nitrate is present in minimal medium, 
transcription from the ogt promoter is activated by NarL binding to the NarL I and NarL II sites. In richer media, Fis represses transcription by binding to Fis I, thereby displacing NarL from the upstream Fis I site. 
Table 1. Strains, plasmids, promoter fragments and primers used in this work.

\begin{tabular}{|c|c|c|}
\hline Name & Details & Source \\
\hline \multicolumn{3}{|c|}{ Bacterial strains. } \\
\hline JCB387 & $\Delta$ nir $\Delta l a c$ & [53] \\
\hline JCB3883 & JCB387 $\Delta$ narL & [54] \\
\hline JCB3871 & JCB387 fis985 (str / spc $\left.{ }^{R}\right)$ & \\
\hline JCB3911 & $\mathrm{JCB} 387 \Delta f n r\left(\mathrm{~cm}^{\mathrm{R}}\right)$ & \\
\hline \multicolumn{3}{|c|}{ Bacterial plasmids } \\
\hline pSR & pBR322 derivative containing transcription terminator & [14] \\
\hline pRW50 & $\begin{array}{l}\text { Broad-host-range lacZ fusion vector for cloning promoters } \\
\text { on EcoRI-Hindlll fragments: contains the RK2 origin of } \\
\text { replication and encodes } T c^{R}\end{array}$ & [15] \\
\hline \multicolumn{3}{|c|}{ Promoter fragments (all EcoRI-HindIII fragments) } \\
\hline yeaR100 & $\begin{array}{l}\text { E. coli yeaR promoter fragment carrying nucleotide } \\
\text { sequences from }-294 \text { to }+96 \text {. }\end{array}$ & This work \\
\hline ogt100 & $\begin{array}{l}\text { E. coli ogt promoter fragment carrying nucleotide } \\
\text { sequences from }-269 \text { to }+51 \text {. }\end{array}$ & This work \\
\hline ogt102 & $\begin{array}{l}\text { Fragment ogt100 carrying } C \text { to } G \text { and } T \text { to } C \text { substitutions } \\
\text { at positions }-84 \text { and }-73 \text {. }\end{array}$ & This work \\
\hline ogt104 & $\begin{array}{l}\text { Fragment ogt100 carrying } T \text { to } G \text { and } G \text { to } C \text { substitutions } \\
\text { at positions }-51 \text { and }-40 \text {. }\end{array}$ & This work \\
\hline \multicolumn{3}{|c|}{ Oligodeoxynucleotide Primers (all are shown 5'-3') } \\
\hline D5431 & ACCTGACGTCTAAGAAACC & \\
\hline pSRDown & ATCCAGATGGAGTTCTGAGG & \\
\hline $\begin{array}{l}\text { pyeaRfw } \\
\text { pyeaRrev }\end{array}$ & $\begin{array}{l}\text { ACCTGTGAATTCGCGACGCTGGAACTGGTG } \\
\text { GTGAACAAGCTTCAGAAAGGCGTTGAGCGCG }\end{array}$ & \\
\hline pogtfw & GCAGAATTCCAATCTGGTCGATTCTCGCC & \\
\hline pogtrev & GCAAAGCTTCATCCGTTCTCTCTTAAGACAAACGTG & \\
\hline pogt102 & $\begin{array}{l}\text { CGCGAAACTGGGTAGTTACTATTCGCTAGTCTTGCCCT } \\
\text { ATCC }\end{array}$ & \\
\hline pogt104 & $\begin{array}{l}\text { GCCCTATCCACTTAGCTTTTTGGTGCTATGGCTGCTGA } \\
\text { TG }\end{array}$ & \\
\hline
\end{tabular}


Table 2. Effects of mutations in the NarL I and NarL II sites at the ogt promoter.

The table lists $\beta$-gala c to sida se activities mea sured in extracts of J CB387 cells carrying derivatives of pRW50 with different promoter fragments. The ogt100 fragment conta ins DNA from positions -269 to +52 from the ogt promoter transcript start point. The ogt102 fragment ca mies substitutions at positions -84 and -73 , which disupt the NarL I binding site, and the ogt104 fragment ca ries substitutions at positions - 51 and 40, which disrupt the NarL II binding site (Figure 4A). Cells were grown in the absence or presence of $20 \mathrm{mM}$ nitrate and the fold induction due to nitrate is listed.

\begin{tabular}{|c|c|c|c|c|c|}
\hline \multirow[b]{2}{*}{ Promoter } & \multicolumn{5}{|c|}{$\beta$-Galactosidase activity } \\
\hline & Mutated Site & minus $\mathrm{NO}_{3}^{-}$ & plus $\mathrm{NO}_{3}^{-}$ & & duction \\
\hline ogt100 & & $93 \pm 1$ & & & 4.7 \\
\hline $\begin{array}{r}\text { ogt102 } \\
1.2\end{array}$ & NarLI $\downarrow$ & & & & $107 \pm 6$ \\
\hline ogt104 & NarL II $\downarrow$ & $56 \pm 2$ & & & 1.6 \\
\hline
\end{tabular}


Figure 1. Squire et al., 2009

A

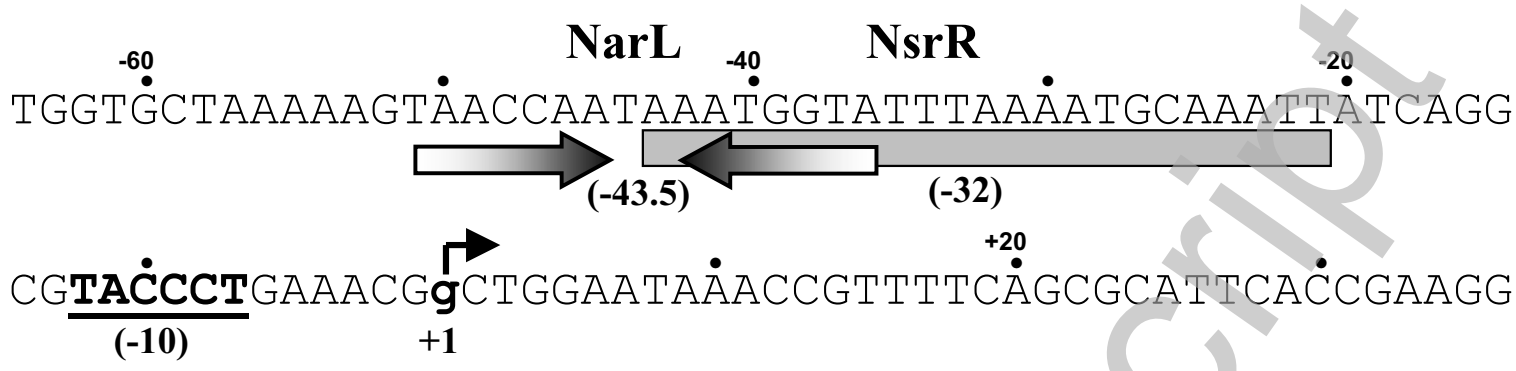

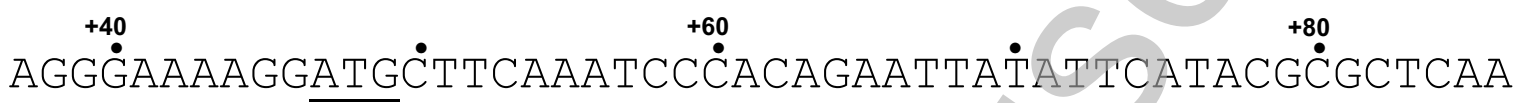

B

D

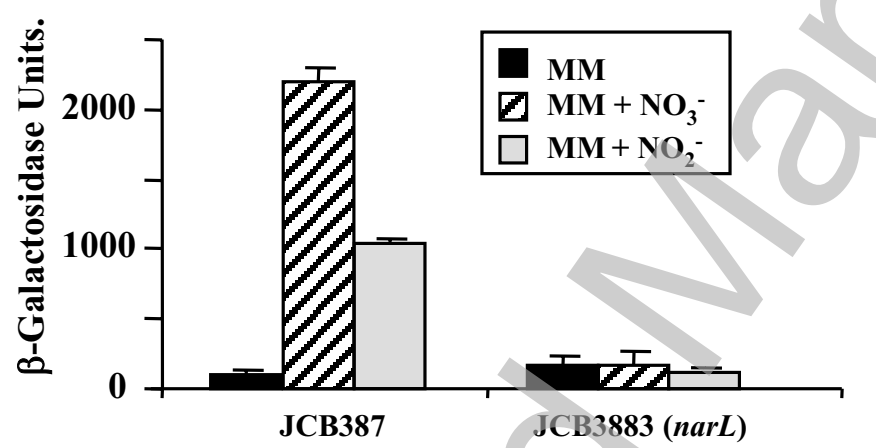

C
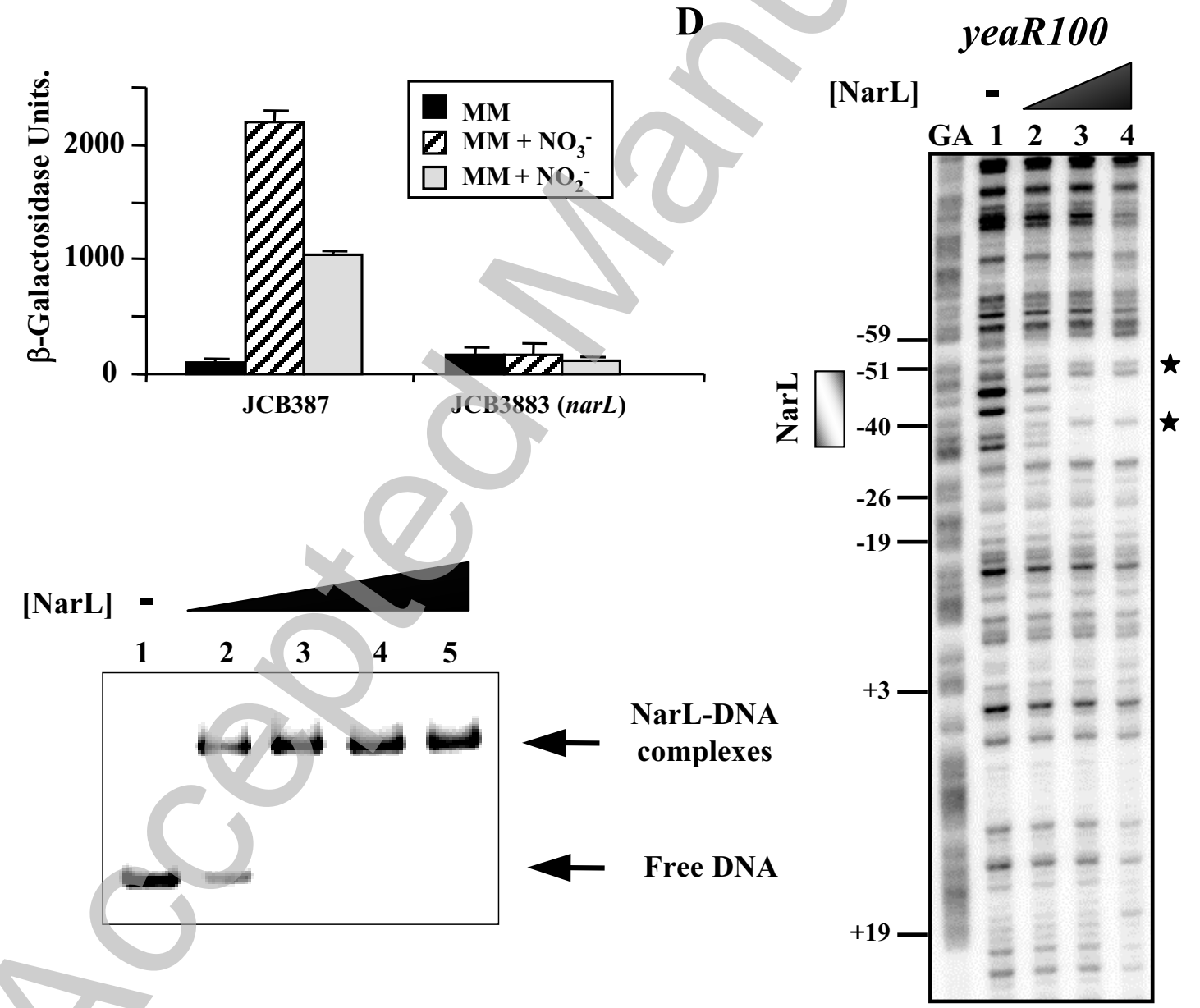

Licenced copy. Copying is not permitted, except with prior permission and as allowed by law. (C) 2009 The Authors Journal compilation (c) 2009 Portland Press Limited 
Figure 2. Squire et al., 2009

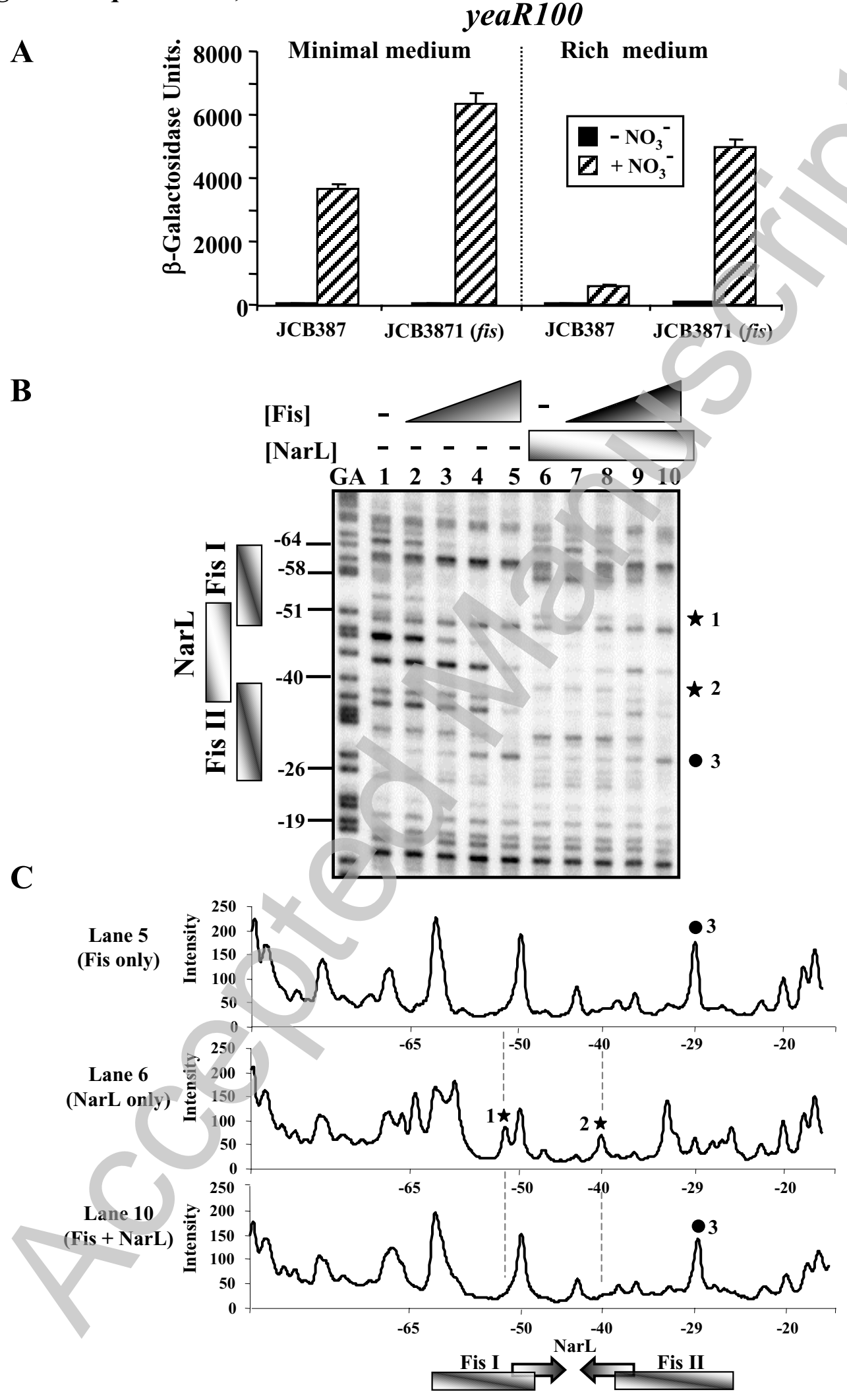


Figure 3. Squire et al., 2009.

A

\section{yeaR100}
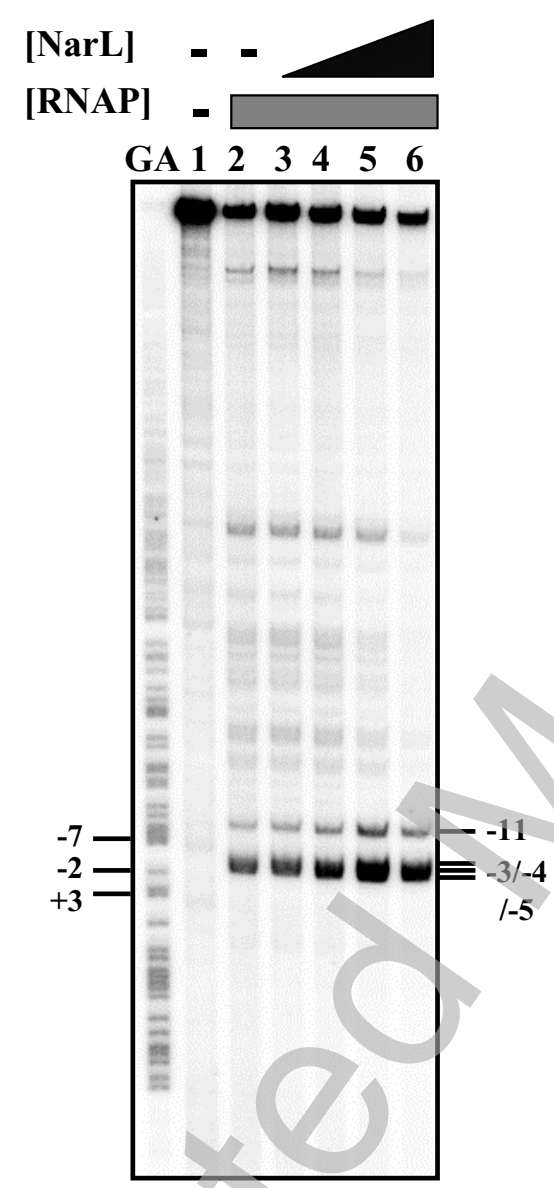

B
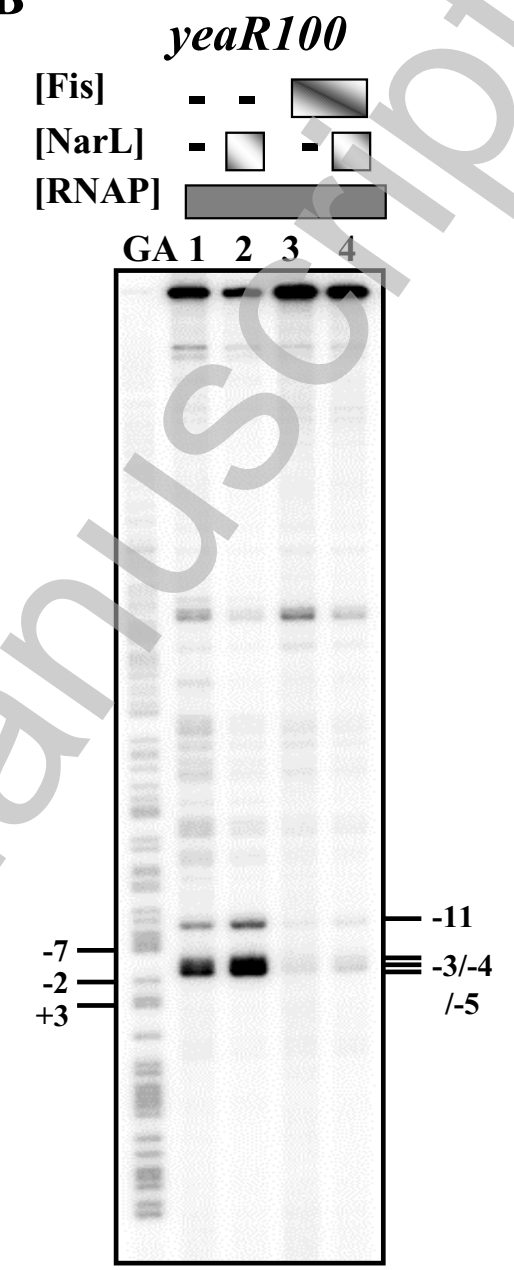
Figure 4. Squire et al., 2009

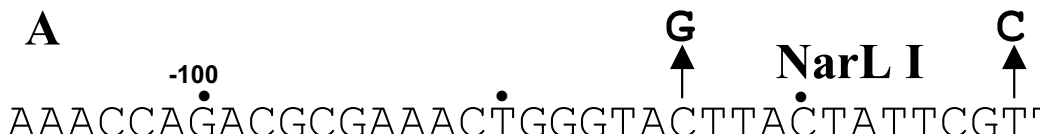

G $\quad \underset{4}{\mathbf{A}} \quad \stackrel{\mathbf{C}}{\mathbf{A}}$

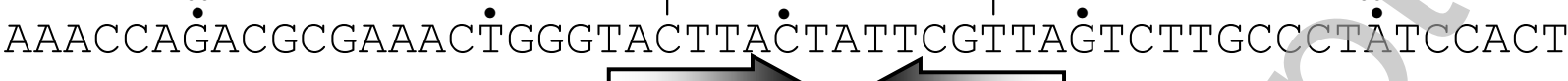

G NarL II C $(-78.5)$

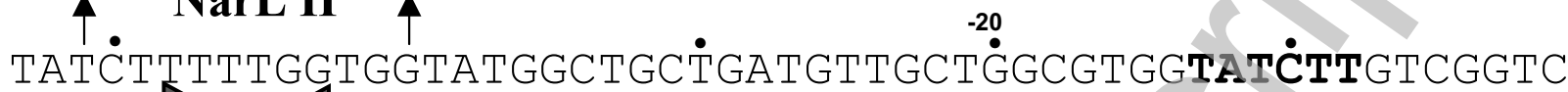
$(-45.5)$

tGCCGATAGGंTCCGGGTATTTACCCACGTTTGTCTTAAGÄGAGAACGGATG $+1$

B

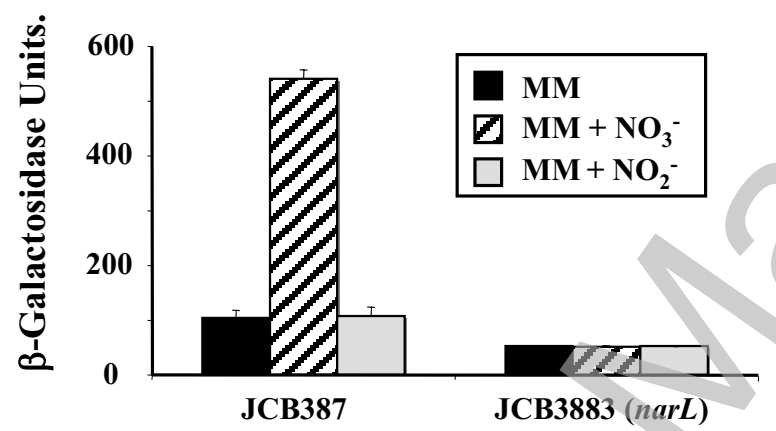

C [NarL] -

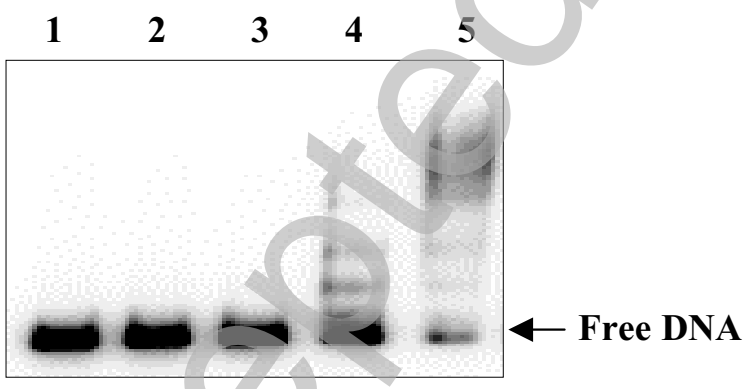

E

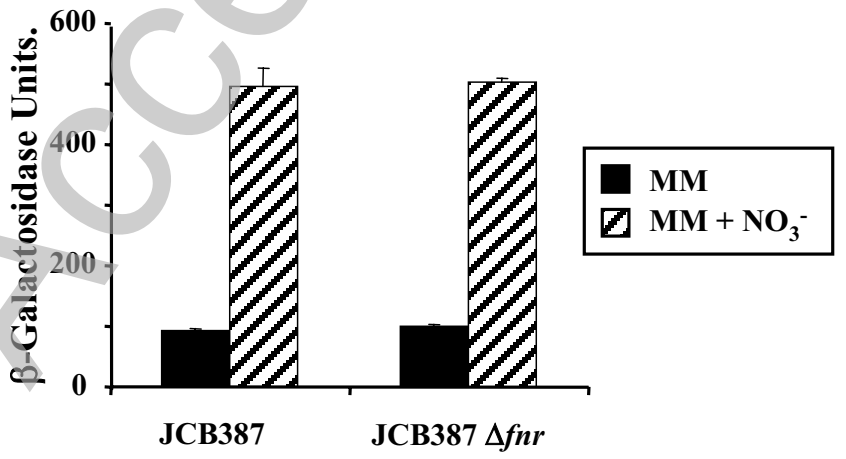

D
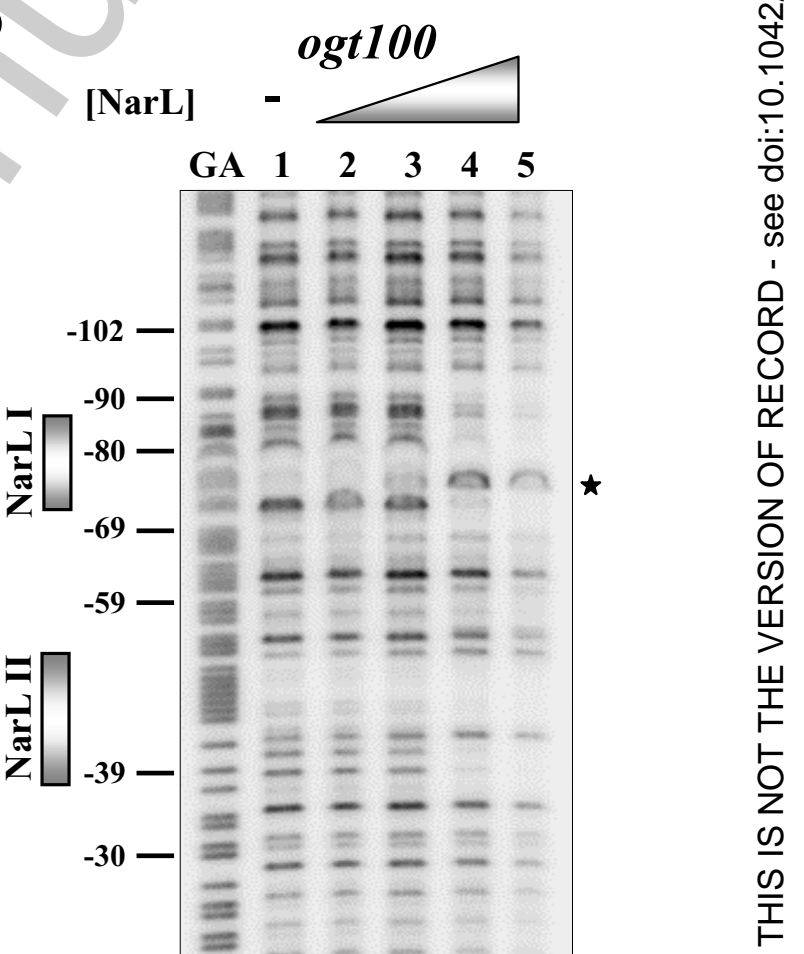
Figure 5. Squire et al., 2009

A

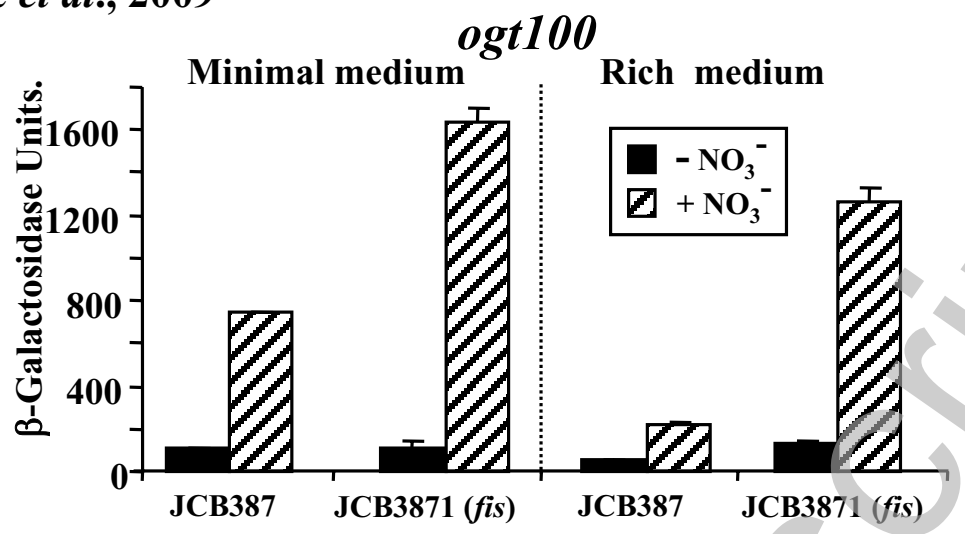

B

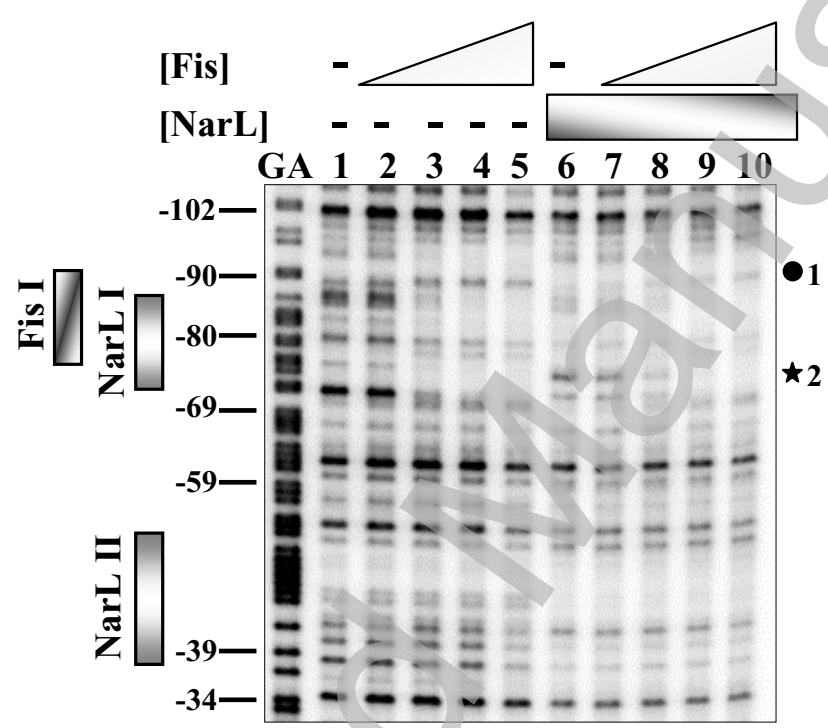

C

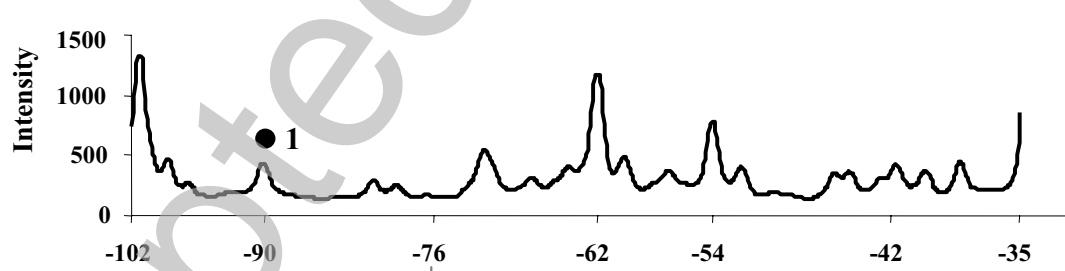

Lane 5

(Fis only)
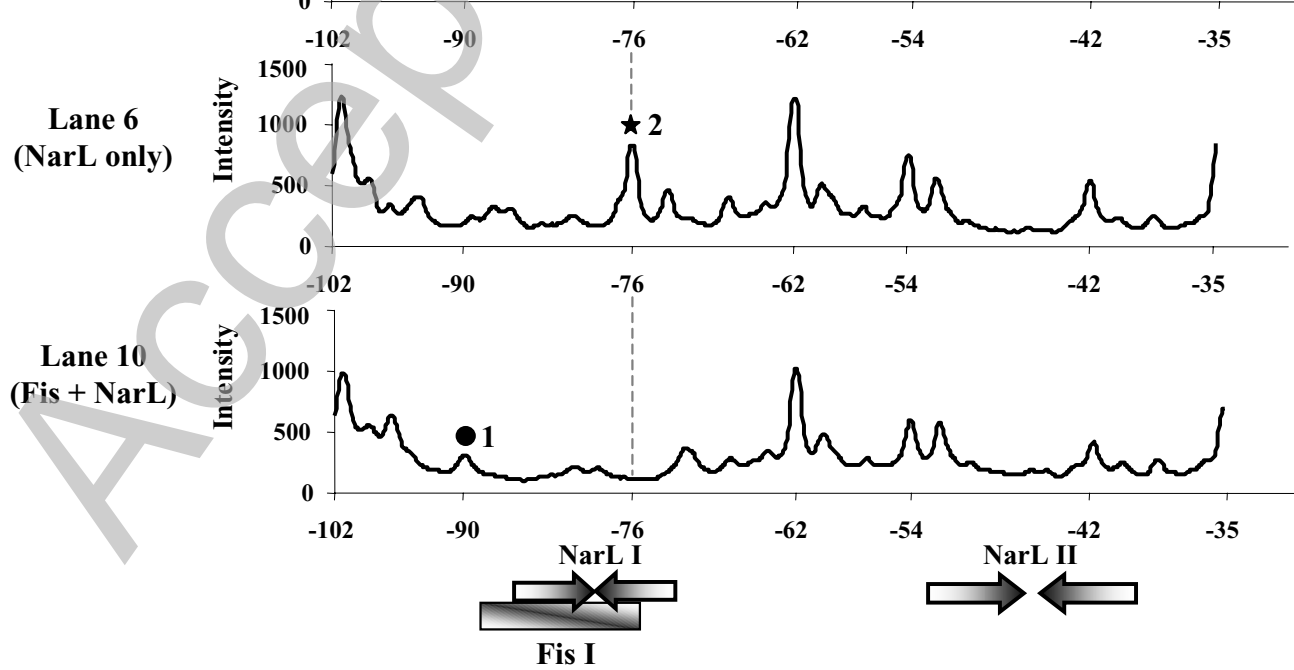

Licenced copy. Copying is not permitted, except with prior permission and as allowed by law. (C) 2009 The Authors Journal compilation (c) 2009 Portland Press Limited 
Figure 6. Squire et al., 2009

\section{A: the yeaR promoter}

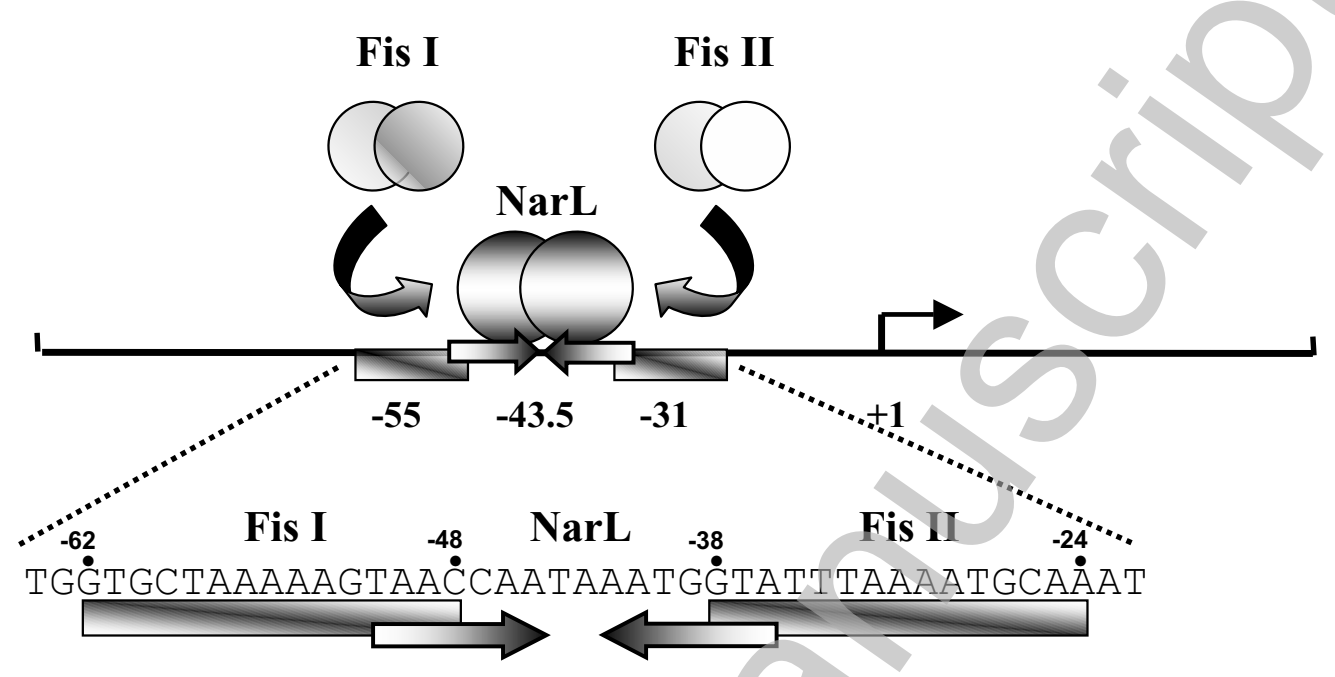

\section{B: the ogt promoter}

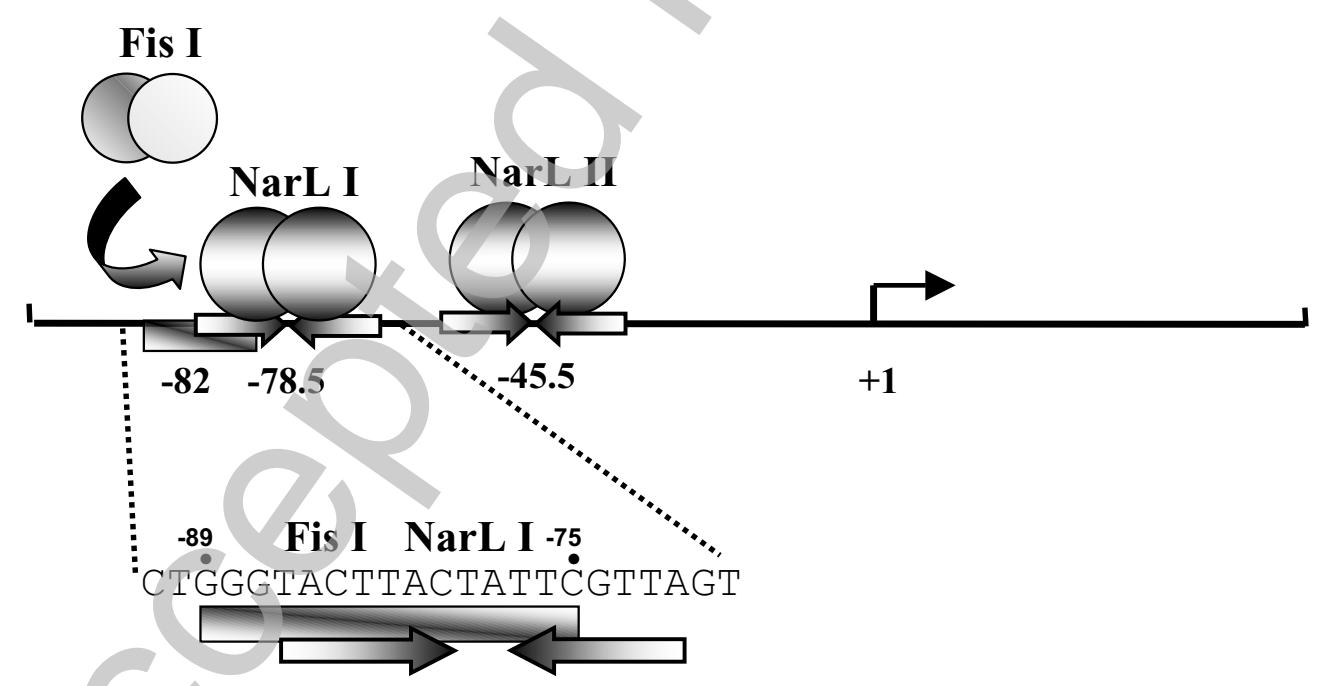

